\title{
Regulation Modelling and Analysis Using Machine Learning During the Covid-19 Pandemic in Russia
}

\author{
Egor TROFIMOV ${ }^{\mathrm{a}}$, Oleg METSKER ${ }^{\mathrm{b}}$, Georgy KOPANITSA ${ }^{\mathrm{c}}$, David PASHOSHEV ${ }^{\mathrm{c}, 1}$ \\ ${ }^{a}$ The All-Russian State University of Justice, Moscow, Russia \\ ${ }^{\mathrm{b}}$ Almazov National Medical Research Centre, Saint-Petersburg, Russia \\ 'ITMO University, Saint-Petersburg, Russia
}

\begin{abstract}
Due to the specific circumstances related to the COVID-19 pandemic, many countries have enforced emergency measures such as self-isolation and restriction of movement and assembly, which are also directly affecting the functioning of their respective public health and judicial systems. The goal of this study is to identify the efficiency of the criminal sanctions in Russia that were introduced in the beginning of COVID-19 outbreak using machine learning methods. We have developed a regression model for the fine handed out, using random forest regression and XGBoost regression, and calculated the features importance parameters. We have developed classification models for the remission of the penalty and for setting a sentence using a gradient boosting classifier.
\end{abstract}

Keywords. COVID-19, machine learning, regulation, Russia

\section{Introduction}

Due to the specific circumstances related to the COVID-19 pandemic, many countries have enforced emergency measures such as self-isolation and restriction of movement and assembly, which are also directly affecting the functioning of their respective public health and judicial systems $[1,2]$.

The breach of any disease containment measures during an emergency period constituted a criminal offense in many countries [3]. For example, Italy [4] was one of the first governments to declare the state of emergency on the 31st of January 2020. The Italian Government formally declared the state of emergency pursuant to Legislative Decree 1/2018 (Civil Protection Code). Later the states started to raise legal restrictions and change the regulations [5].

One of the main issues in many countries was the partition of authority between regional and national officials [6]. This had not only caused political tensions among the authorities themselves, but it resulted in different regulations, which did not allow legal certainty and consistency [7-9]. Various legal practices raised the discussion on the efficiency of the criminal sanctions to slow down the spread of the pandemic [10]. As the spread of pandemic is a complex multifactor, we don't think it is possible to

${ }^{1}$ Corresponding Author: David Paskoshev, ITMO University, Saint-Petersburg, Russia, E-mail: david.d.paskoshev@gmail.com 
accurately identify the influence of only one legal measure [11]. At least it is worth and important to evaluate if the criminal restrictions themselves are efficient and clear to the people, public health and law enforcement services.

The goal of this study is to identify the efficiency of the criminal sanctions in Russia that were introduced in the beginning of COVID-19 outbreak using machine learning methods.

\section{Methods}

We believe that a well working administrative norm should have a low rate of s remission of a sentence, and an average amount of fine closed to the average amount of fine in the norm [12]. To measure the efficiency of the introduced regulation we have calculated features importance for the following outcomes:

- Amount of fine

- Remission of a penalty

- $\quad$ Setting a sentence

\subsection{Data collection}

The data for the study was extracted from the Russian national digital court decision database (http://www.cdep.ru) from the 1st January 2015 to the 30th of September 2020. In total we have extracted 58334 cases with 25682 cases from 2020 . The dataset was randomly split into a training (80\%) and a testing (20\%) datasets.

We have extracted the narrative texts of every case and processed them using a data extraction software that was specially designed for Russian court decision processing [13].

\subsection{Classification and Features importance}

Features importance was analyzed using scikit learn library version 0.23 [14]. The following models were developed to calculate features importance.

We have developed a regression model for fine using a random forest regressor and a XGBoosting regressor, and calculated the features importance parameters.

We have developed classification models for the remission of the penalty and for setting a sentence using a gradient boosting classifier.

Each experiment ran in the setting of stratified 4-fold cross-validation i.e., random $80 \%$ of training dataset was used for training and random $20 \%$ of training dataset for testing. Target class ratios in the folds were preserved. After determining the optimal dataset and model parameters, we performed a validation with the testing dataset. As an additional performance assessment score, we used AUC of ROC, which represents the trade-off between sensitivity and specificity of the model.

Shapley values we calculated for the classification models on the remission of the penalty and setting a sentence. 


\section{Results}

Feature's importance analysis for the prediction of amount of a fine is presented in Figure 1. The features "minimum" and "minimal" support the conclusion that the courts tended for a minimal possible sentence.

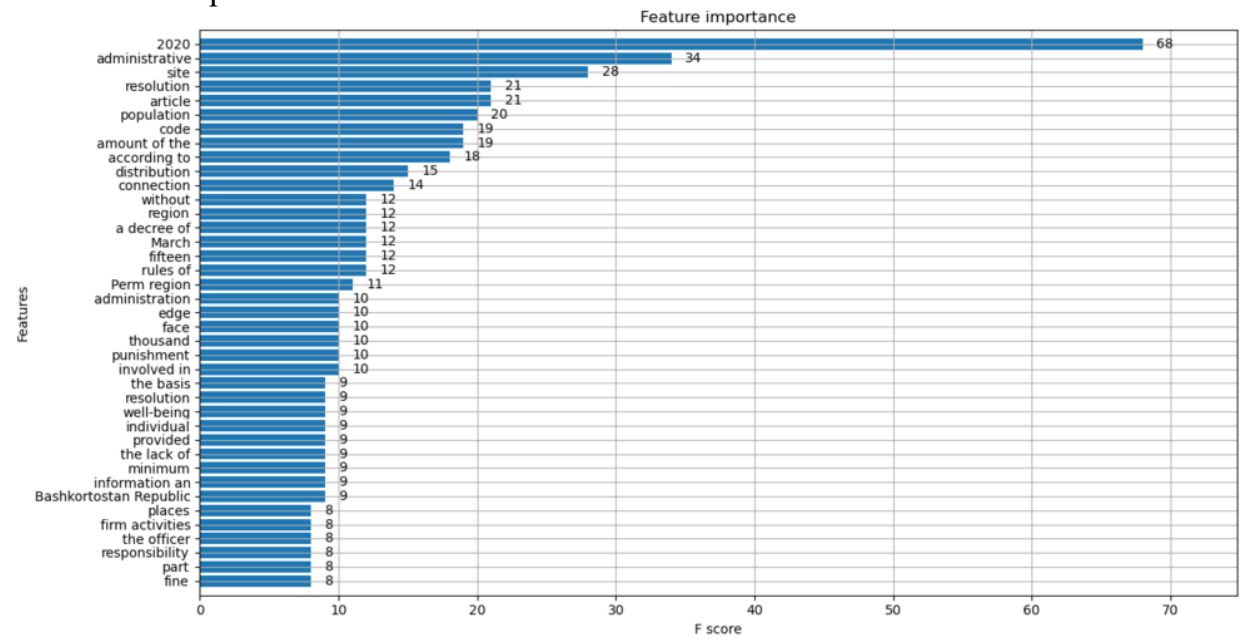

Figure 1. Features importance for the amount of fine

Figure 2 presents the Shapley values for the remission of penalty.

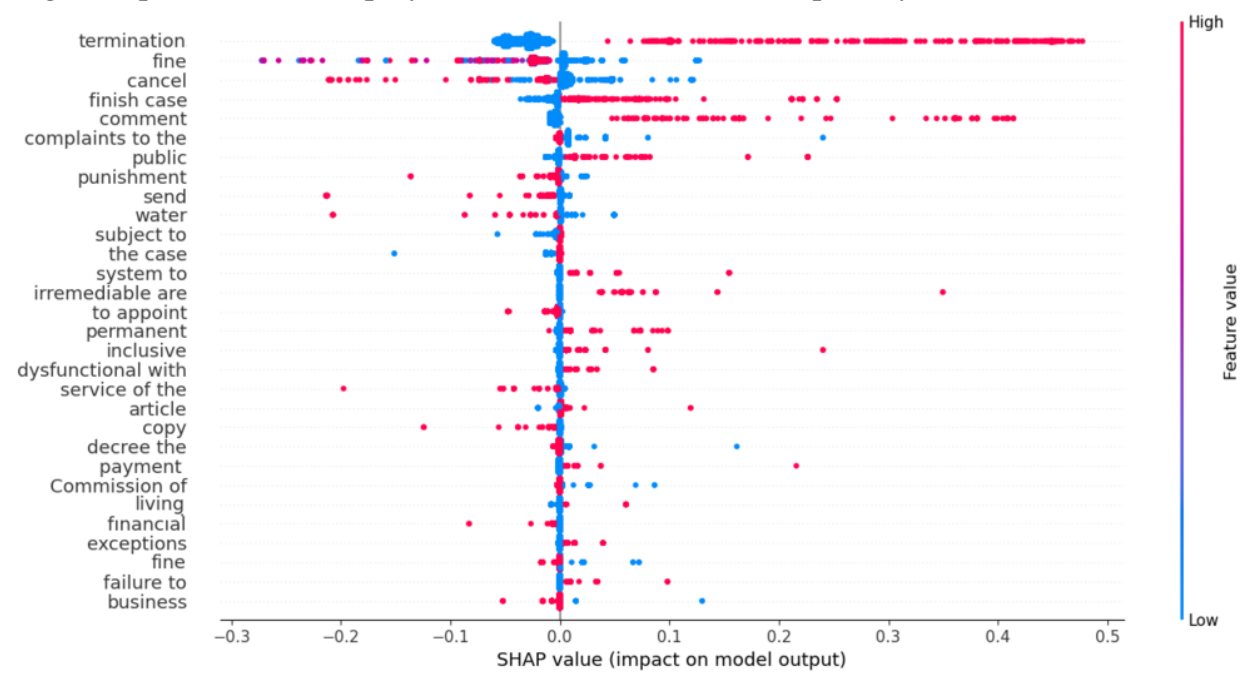

Figure 2. SHAP values for the remission of penalty

1) The feature «Formally» means cancellation of an earlier ruling and termination of proceedings when the violation was formal but not significant (e.g. a citizen moved a little more away from home than allowed).

2) The feature «intractable» supports the conclusion that the courts tended to terminate the cases due to presumption of innocence when all intractable doubts are interpreted in favor of the offender, which is important if the laws and rules are too confusing or unclear. 


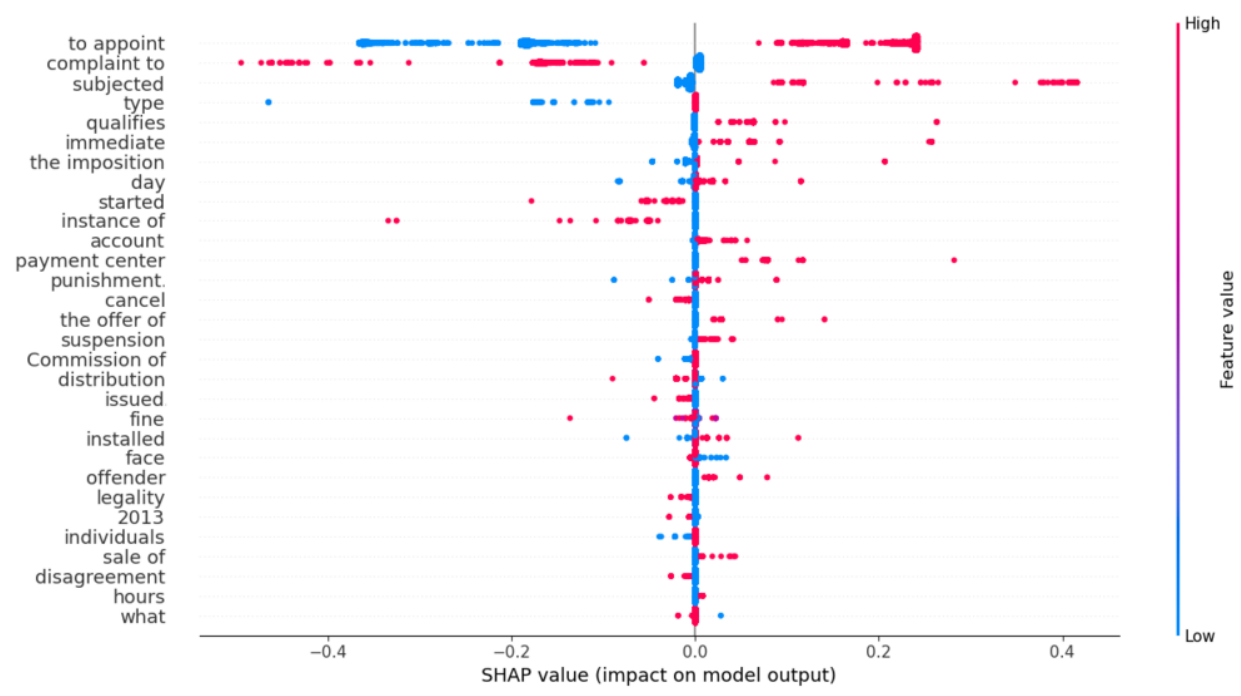

Figure 3. SHAP values for the setting a sentence

Here we can observe the logical result that indicate the correctness of the data extraction. The terms "to appoint", "subjected", "qualify", "impose", "pay", "punish", "suspend", "offender" - are all related to the assigning a punishment, so the red dots (figure 3) are on the right side.

The terms "started", "annul", "disagree" - indicate the termination of the started proceedings and annulment of the earlier decision in the case, so the red dots (figure 3) are on the left side.

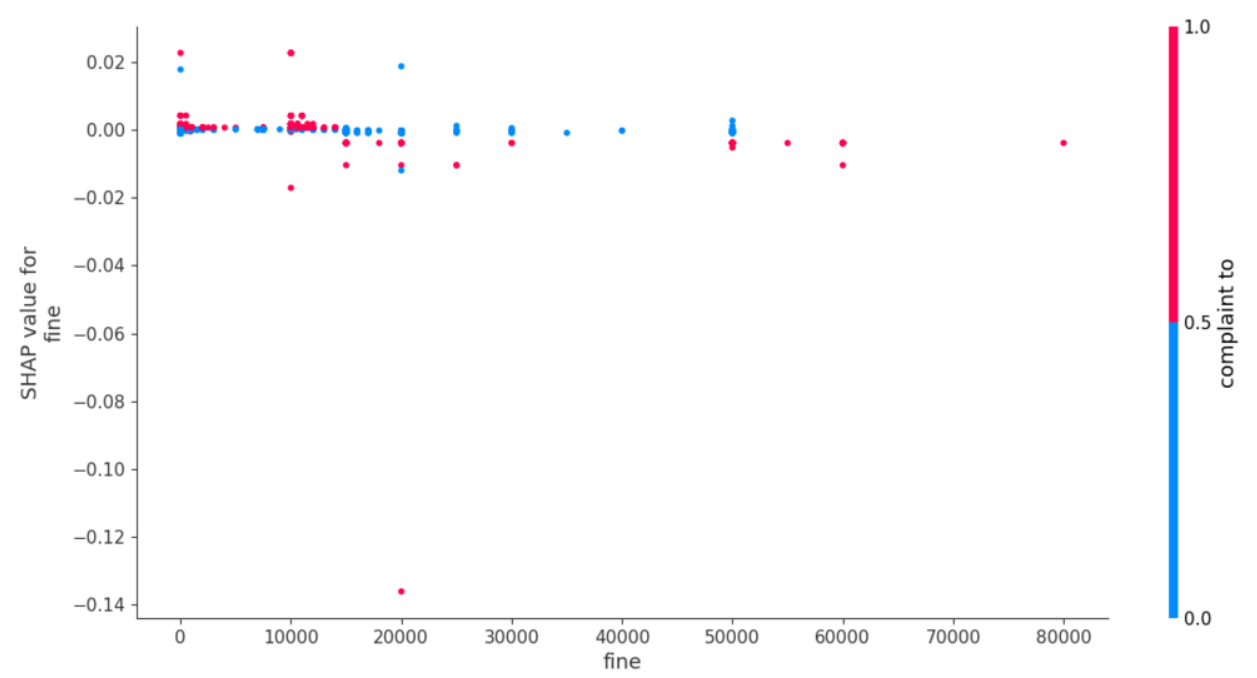

Figure 4. Dependency plot of the amount of the fine and the presence of the complaint

The plot (Figure 4) clearly shows that usually the complaint is associated with the appointment of a fine of fifteen thousand rubles positively on the appointment of punishment while after fifteen thousand rubles it is negative or not related. 


\section{Discussion}

The new legislation came into force only on April 1. Assuming that no more violations were revealed in the first half of the year than a year earlier, we can conclude that for April, May and June (three months) of 2020 about 26685 cases were considered under paragraph 2 and paragraph 3 of Article 6.3 of the Code. The analysis showed that:

1) Almost every sixth case was terminated because there were no signs of an offence or because of the insignificance of the offence;

2) cases against legal entities constitute a negligible proportion (the number of legal entities held liable for violations in the sanitary-epidemiological area has decreased as compared to previous years);

3) Out of 10 thousand individuals who were punished, about 10 percent were individual entrepreneurs and about 5 percent were officials (the rest 85 percent or more - ordinary individuals);

4) warnings and fines were imposed on about 9 thousand individuals;

5) the average fine was about 18 thousand rubles, i.e. for all categories of individuals (individual entrepreneurs, officials, other individuals) the fine is approximately at the minimum defined in the article 6.3;

6) the courts have actively exercised their right to impose a penalty below the minimum statutory penalty, doing so in every tenth case. Although a year earlier, during the same period (quarter), all courts in Russia made such a decision only once. The probability of such condescension in cases on paragraphs 2 and 3 of Article 6.3 of the Code was about 10 percent, while for other violations in the sanitary-epidemiological sphere - about 0.04 percent.

\section{Conclusion}

Our findings prove that the law norms and explanations are too abstract and uncertain by the number of canceled cases and the amount of the decisions with a minimum fine. The results of the study can be beneficial for the analysis of the legal practice and improving legislation and law enforcement in the situations of pandemic.

\section{Acknowledgement}

This work financially supported by the government of the Russian Federation through the ITMO fellowship and professorship program. The reported study was funded by RFBR, project number 20-011-00837.

\section{References}

[1] Morris DH, Rossine FW, Plotkin JB, Levin SA. Optimal, near-optimal, and robust epidemic control. Communications Physics 2021; 4(1): 1-8. doi:10.1038/s42005-021-00570-y.

[2] Xu C, Luo X, Yu C, Cao S-J. The 2019-nCoV epidemic control strategies and future challenges of building healthy smart cities. Indoor Built Environment 2020; 29(5): 639-644. doi:10.1177/1420326X20910408. 
[3] Rosenbaum L. Facing Covid-19 in Italy - Ethics, Logistics, and Therapeutics on the Epidemic's Front Line, N Engl J Med. 2020 May 14; 382(20): 1873-1875. doi: 10.1056/NEJMp2005492. Epub 2020 Mar 18.

[4] Canestrini N. Covid-19 Italian emergency legislation and infection of the rule of law. New Journal of European Criminal Law 2020; 11(2): 116-122. doi:10.1177/2032284420934669.

[5] Pinkas J, Jankowski M, Szumowski L, Lusawa A, et al. Public health interventions to mitigate early spread of SARS-CoV-2 in Poland. Med Sci Monit. 2020 Apr 13;26:e924730. doi:10.12659/MSM.924730.

[6] Gostin LO, Hodge JG. US Emergency Legal Responses to Novel Coronavirus: Balancing Public Health and Civil Liberties. JAMA 2020 Mar 24;323(12):1131-1132. doi: 10.1001/jama.2020.2025.

[7] Pinheiro VM, Ilarraz M, Mestriner MT. The impacts of the COVID-19 crisis on the Brazilian legal system-a report on the functioning of the branches of the government and on the legal scrutiny of their activities. The Theory and Practice of Legislation 2020; 8: 193-212; https://doi.org/10.1080/20508840.2020.1790104

[8] Parmet WE, Sinha MS. Covid-19 - The Law and Limits of Quarantine. N Engl J Med. 2020 Apr 9;382(15):e28. doi: 10.1056/NEJMp2004211. Epub 2020 Mar 18.

[9] Chinazzi M, Davis JT, Ajelli M, Gioannini C, et al. The effect of travel restrictions on the spread of the 2019 novel coronavirus (COVID-19) outbreak. Science. 2020 Apr 24;368(6489):395-400. doi: 10.1126/science.aba9757. Epub 2020 Mar 6.

[10] Stogner J, Miller BL, McLean K. Police Stress, Mental Health, and Resiliency during the COVID-19 Pandemic. Am J Crim Justice. 2020 Jun 26: 1-13. doi: 10.1007/s12103-020-09548-y [Epub ahead of print]

[11] Miller JM, Blumstein A. Crime, Justice \& the COVID-19 Pandemic: Toward a National Research Agenda, American Journal of Criminal Justice 2020; 45: 515-524. doi:10.1007/s12103-020-09555-z.

[12] Voigt S. How to Measure the Rule of Law, Kyklos. May 2012; 65(2): 262-284. doi:10.1111/j.14676435.2012.00538.x.

[13] Metsker O, Trofimov E, Grechishcheva S. Natural Language Processing of Russian Court Decisions for Digital Indicators Mapping for Oversight Process Control Efficiency: Disobeying a Police Officer Case, in: Communications in Computer and Information Science, 2020; 1135: . doi:10.1007/978-3-030-39296322.

[14] Pedregosa F, Varoquaux G, Gramfort A, Michel V, et al. Scikit-learn: Machine learning in Python. Journal of Machine Learning Research. 2011;12(85):2825-2830. 